\title{
Sylvatic triatominae: a new challenge in vector control transmission
}

\author{
Felipe Guhl/ ${ }^{+}$, Nestor Pinto, Germán Aguilera \\ Centro de Investigaciones en Microbiología y Parasitología Tropical, Departamento de Ciencias Biológicas, Apartado Aéreo 4976, \\ Bogotá, Colombia
}

Over the last 10 years, Uruguay, Chile and Brazil have been certified as being free from disease transmission by Triatoma infestans, the main domiciliated vector for Chagas disease in the Southern Cone countries. This demonstrates that programmes addressing the vector for the disease's transmission are effective. These programmes have resulted in a dramatic decrease in the incidence of Chagas disease in Latin America. Guatemala was certified a few months ago as being free from disease transmission by Rhodnius prolixus, the main domiciliated vector for Chagas disease in Central American countries. However, the main concern for different countries' current control programmes is the continuity and sustainability of future vector control actions. The prevalence and incidence figures for individuals infected by Trypanosoma cruzi in Mexico and Andean and Central American countries highlights the need for broadened strategies in the struggle against the disease and its vectors. A number of triatomine insects are parasite vectors, each with a different life history. Therefore, it is important that new vector control strategies be proposed, keeping in mind that some species are found in peridomiciliary areas and wild ecotopes. The only viable control strategy is to reduce human interactions with vector insects so that the re-infestation and re-colonisation of human habitats will not take place.

Key words: Chagas disease - triatomine - vector - control

Domiciliated triatomines are the main agents responsible for the transmission of Trypanosoma cruzi infection in humans. Seven species may be capable of colonising human dwellings in America: Rhodnius prolixus, Rhodnius pallescens, Triatoma dimidiata, Triatoma infestans, Triatoma brasiliensis, Triatoma sordida and Panstrongylus megistus. Four of these species present a high degree of adaptation to human housing, including the peridomiciliary area ( $R$. prolixus, T. infestans, T. dimidiata and $T$. brasiliensis). The other species are less efficient vectors and are more limited in their geographic distribution, except for P. megistus (WHO 2007).

The T. cruzi transmission rate is influenced by many factors, including insect density, the reproductive frequency of $T$. cruzi, the possibility of insect interactions with humans or other important reservoirs, their longevity, human and reservoir susceptibility to infection, vector and reservoir distribution related to human populations, vector and reservoir infection rates and the duration of parasitaemia (Schofield 1994).

\section{Vectorial control}

Different from autochthonous vector species, domiciliated species such as T. infestans in the Southern Cone and $R$. prolixus in Central America are considered to be introduced species that have become adapted to human habitat due to their passive transport by human migra-

+ Corresponding author: fguhl@uniandes.edu.co

Received 17 March 2009

Accepted 15 May 2009 tion over time. They show a high degree of susceptibility to pyrethroid insecticides.

When it is known that vectors have become domiciliated and are actively responsible for transmission, spraying residual action insecticides is not questioned, given that the insecticides represent a means of immediate control to alleviate the suffering of inhabitants who have been in contact with vector insects within the last 6-8 months. Residual action insecticides are not permanent. After the product's residual action time has passed, a second spraying cycle is necessary. This, in turn, is temporary, and it is possible for the house to become reinfested once again. This is when control programmes must establish an entomological surveillance component to impede re-infestation efforts, especially by adventitious sylvatic species.

It is clear that using a particular control method does not exclude using another one. Chemical control must complement other efforts such as improving rural housing, managing the environment and ordering the peridomiciliary area where autochthonous vector insect species are frequently found.

A series of standards and stages in the technical and operational levels must be followed consistently for the control programme to be effective. To control Chagas disease, it is necessary to prevent parasite transmission by its two main mechanisms (vectorial and transfusional) and to complement this prevention with a secondary level of prevention in terms of medical and social attention for infected people. The key elements to such a programme, which has been proven successful, have been previously described by several authors (Schofield \& Dias 1999, Dias et al. 2002, WHO 2002, Moncayo 2003, Guhl et al. 2005b, Yamagata \& Nakagawa 2006). 
A key element for the success of national and regional programmes is the continuity of action. There are records of failures and reversals in programmes that began well but that did not have the strength or priority to be consolidated and maintained. There are several elements that must come into play to achieve a sustainable programme in both nationalised systems and decentralised operations, with the bulk of these elements taking place during the surveillance stage (Silveira \& Rezende 1984, Guhl \& Schofield 2002). The surveillance stage is important for a general approach and for the political line of argument needed for prioritising action. These evaluations are fundamental for raising awareness among local authorities and the population itself, particularly with increasing decentralisation and community participation.

The sub-regional approach adopted in American countries for facing the problem of Chagas disease is based on entomological and epidemiological criteria. However, the objectives are generally centred on eliminating the parasite's vectorial and transfusional transmission and establishing intervention strategies differentiated according to the aforementioned criteria. Continental initiatives have been created for controlling Chagas disease in Mexico, the Southern Cone, Andean and Central American countries and the Amazonian Region (Guhl 2007a, b).

Three Southern Cone countries (Uruguay, Chile and Brazil) have obtained a Pan-American Health Organization certificate for the disruption of Chagas disease transmission by T. infestans, a certificate that has been endorsed by all of the subregion's ministries of health. This constitutes a very important achievement in terms of reducing incidence in the subregion (TDR 1998, 1999). Argentina has interrupted transmission in five of its 19 endemic provinces and the other Southern Cone countries have active vector control programmes as well (Dias 2007, WHO 2007).

The goals achieved to date have shown that the tools for establishing vector control programmes, thereby eliminating domiciliated vector insects, are economically affordable by the ministries of health in Latin American countries.

The Amazonian Initiative for vector control has been recently created, recognising Chagas disease as an emerging problem that must be suitably monitored by all nine countries making up the Amazon Basin (Coura et al. 2002). In spite of having been considered to be a non-endemic region for a long time, ecological changes associated with intense human migration have occurred and the number of cases of human infection has been increasing exponentially over the last decade. Sylvatic cycles of $T$. cruzi transmission are abundant in the Amazon and close to 20 triatomine species have already been reported. All of them may be potential vectors. Given that transmission to humans depends on suitable contact between vector populations and people, the main risk for human infection falls on triatomine species that are relatively advanced in transition from a sylvatic habitat to a peridomestic and domestic one, particularly Rhodnius robustus, Rhodnius pictipes, Rhodnius brethesi, Panstrongylus geniculatus and Triatoma maculata. Other species imported to the Amazon from other places (i.e., species associated with human migrations and new waves of colonisation) and adventitious Amazonian species, which may fly into houses and contaminate drinks and food, may represent additional risks. It is important that ongoing control and surveillance programmes be maintained in the immediate future and, above all, that epidemiological data be handled with caution (WHO 2007).

\section{Defining variables and risk criteria involved in deci- sion-making}

When defining priorities for controlling vectorial transmission of Chagas disease based on risk criteria, it is important to have decision-making instruments aimed at achieving the objectives proposed in the control programmes. These instruments allow health authorities to take action, leading to a more suitable rationalisation for the resources spent for vectorial control activities, boosting efforts and emphasising evidence-based action (Silveira 2003, OPS 2004, Guhl et al. 2005b).

\section{Epidemiological stratification}

This consists of grouping elements that lead to similar events so that a determined risk can be presented for the occurrence of a phenomenon. Characterising the strata operationally allows a hierarchical selection of population groups or territories for applying differentiated interventions.

Stratification is useful for identifying population groups that have similar risks for a certain health event and at the same time identifying territorial spaces linked to population groups, thereby allowing them to be grouped into conglomerates so that their indicators can be compared.

Epidemiological stratification can be approached in different ways, with the most used being single indicator stratification, summarised indexes, epidemiological stratification of risks and weighted index stratification (Guhl et al. 2005b).

The stages for stratifying risks have been presented in a OPS technical report (2004) and may be summarised as follows: (i) studying the health problem and its tendency during the last few years for determining priority areas and populations; (ii) identifying and measuring risks; (iii) forming epidemiological risk strata by organising them into a hierarchy of factors carrying greater weight; (iv) selecting the most effective interventions; (v) planning the interventions; (vi) identifying structure, process and results indicators; (vii) executing the interventions and (viii) evaluation.

Different risk levels must be considered in the evolution of Chagas disease, from the risk of domiciliation and colonisation of vectors to the risk of becoming sick or dying. The primary risk is infected vector - susceptible human contact. The risks of vectors becoming domiciliated must also be estimated, as must the persistence of domiciliary infestation, the risk of transmission and the eventual risk of re-infestation and re-establishment of vectorial transmission (Pinto et al. 2005). 


\section{The current situation and future perspectives}

The progress of control activities against $T$. cruzi vector insects present on the continent has been slow in some countries for a variety of reasons and control interventions have still not been set up in all geographical areas occupied by the target species. The reasons are partly due to ignorance of the vector populations' biological characteristics and the consequent uncertainty regarding what the most appropriate control measures and strategies should be. This leads us to conclude that in spite of the success achieved in the Southern Cone, there is still a long way to go. It is imperative that mechanisms be established that lead to the continuity of control action in programmes that have consolidated their action including (in addition to insecticide spraying) entomological surveillance and improving rural life. Future efforts cannot continue to be so undefined. Selective control and surveillance action are required due to the risk represented by possible domiciliary re-infestations. Table summarises the actions recommended for controlling autochthonous or introduced triatomine species in different control initiatives and geographical areas in the Americas.

\section{Wild species and the problem of re-infestation}

The sylvatic species sporadically invading human dwellings must be recognised and their ecology and behaviour must be studied in their natural setting so that the domiciliation process may be better understood, enabling new strategies to become established for their surveillance. Additional transmission measurements are needed, as is a dynamic, ongoing instruction programme providing information about the disease, control measures and the importance of keeping the domiciliary and peridomiciliary areas free from vector insects. Palm trees (particularly Attalea butyracea in Colombia and Venezuela) are widely distributed and constitute a tremendously large faunistic reserve. These palms are also used to shade people's housing, and juice and wine are produced from their fruit. Mammalian reservoirs for

TABLE

Action to be taken for controlling autoctonous or introduced triatomine species in different control initiatives in the Americas ${ }^{a}$

Region Perspectives

Southern countries and Southern Perú

Andean and Central-American countries' initiatives

Amazonian countries' initiatives

All continental initiatives
Introduced triatomine species present a high degree of domiciliation (i.e., Triatoma infestans) and are vulnerable to latest generation insecticide action and can thus be eliminated, as has been demonstrated in Brazil, Chile and Uruguay. It is totally feasible that the other countries involved in the Southern Cone and Southern Peru initiative achieve this goal in the short and medium-term. Autochthonous species (such as Triatoma brasiliensis, Panstrongylus megistus and Triatoma sordida) require an ongoing entomological surveillance programme given that they can adapt to human habitat.

Introduced triatomine species presenting a high degree of domiciliation (such as Rhodnius prolixus) in extensive areas of Colombia, Venezuela and in most Central-American countries (except for El Salvador and Panamá), the same as Rhodnius ecuadoriensis in Ecuador and Northern Peru, are vulnerable to insecticide action and can thus be eliminated as has been demonstrated with $R$. prolixus in some regions of Guatemala and Venezuela. Peridomiciliated species (such as Triatoma dimidiata) require the physical management of human habitations and the peridomiciliary environment, as well as sustained entomological surveillance programmes. Some species from silvatic habitats represent a challenge for future control action, as in the case of silvatic $R$. prolixus populations in Venezuela and Colombia.

The Amazonian initiative for vectorial control of Chagas' disease is formed by nine South-American countries, representing an important challenge in terms of entomological surveillance and merits special attention in the immediate future. Different Rhodnius and Panstrongylus species present in the Amazon Region must be considered to be epidemiologically important potential vectors.

It must be born in mind that, in spite of the achievements made in different regional initiatives, Chagas' disease persists in Latin-America given that it represents a silvatic enzooty and anthropozoonosis and therefore requires long-term surveillance and control action.

$a$ : data from Guhl 2007a. 
triatomines are commonly found in the crowns of these palm trees. Several reports have indicated high colonisation and natural infection indexes. Over 2,000 R. prolixus were captured in a $102 \mathrm{~A}$. butyracea palm transect in the Eastern Plains of Colombia in the Casanare department. A $100 \%$ infestation index in palm trees and $67 \%$ natural infection index were reported in triatomines and $89 \%$ of Didelphis marsupialis studied were found to be infected with T. cruzi (Pinto et al. 2005).

Elaeis guineensis (African palm crops) have experienced a huge boom in the foothills of the ColombianVenezuelan plain (12\% annual planting growth). The oil obtained from this palm's fruit is one of the most profitable products in the world, and 600 tons of fruit per hectare/year can be harvested after a 24-month growth period. Colombia supplied 524,000 of the 21.2 million tons produced around the world in 2000. The crop has increased so much that production for 2007 has been doubled since the year 2000. This means that extensive artificial crops are beginning to occupy sites previously occupied by natural ecosystems. Such intervention has not only accelerated changes in the landscape, but it has also reduced the capacity of crops grown for nutritional ends and generated new transmission cycles for tropical diseases. The possible long-term impact has not been evaluated. A study of these oil palms carried out in Colombia's Eastern Plains area revealed a 46.66\% infestation index in palm trees, a $41.17 \% R$. prolixus natural infection index and a $28.57 \%$ infection index in insects captured in the crops' installations (Guhl et al. 2005a). These results suggest that high domiciliary re-infestation indexes (18\% of dwellings) analysed from 2004-2005 in the Casanare Department were the result of re-infestation by sylvatic triatomines despite having been sprayed with pyrethroids.

A recent study carried out in Venezuela (Fitzpatrick et al. 2008) showed that domestic infestations of R. prolixus have persisted despite the vector control measures used over the last four decades. Repeated colonisation of houses by sylvatic $R$. prolixus populations may explain the difficulties involved in vectorial control. However, a controversy has arisen concerning the existence of sylvatic $R$. prolixus populations. Some have suggested that all sylvatic populations are actually $R$. robustus (a secondary species having lesser epidemiological importance) and not $R$. prolixus. In this study (Fitzpatrick et al. 2008) triatomine species captured in palms across Venezuela were shown to be $R$. prolixus by direct sequencing (mtcytb, D2) and microsatellite analysis. These insects were genetically identical to the domestic populations.

Insect dispersion between sylvatic and domestic ecotopes occurs actively and passively, as can be seen when palm leaves are used in roofing of houses, since the $R$. prolixus female sticks her eggs to palm leaves. Substituting palm leaves with other materials for roofing houses has led to a reduction of this risk factor. Active transport may also occur, with insects attracted by house lights and then flying into houses.

In light of the studies from Colombia and Venezuela, it is clear that sylvatic $R$. prolixus populations represent an important risk factor for $T$. cruzi transmission to hu- mans. They also represent a new challenge for vector control programmes in the endemic Colombian-Venezuelan region. Control programmes must therefore apply new strategies for avoiding insect-human contact using materials impregnated with insecticide such as curtains and mosquito netting, using other materials besides palm leaves for roofing and coming up with alternatives for suitably managing the environment and ordering the peridomici liary area to prevent triatomines from colonising homes.

\section{REFERENCES}

Coura JR, Junqueira A, Fernandes O, Valente A, Miles MA 2002. Emerging Chagas' disease in the Amazonian Brazil. Trends Parasitol 18: 171-176.

Dias JCP 2007. Southern Cone initiative for the elimination of domestic populations of Triatoma infestans and the interruption of transfusion Chagas' disease: historical aspects, present situation and perspectives. Mem Inst Oswaldo Cruz 102: 11-18.

Dias JCP, Silveira AC, Schofield CJ 2002. The impact of Chagas' disease control in Latin America. A review. Mem Inst Oswaldo Cruz 97: 603-612.

Fitzpatrick S, Feliciangeli D, Sanchez-Martin M, Monteiro F, Miles MA 2008. Molecular genetics reveal that silvatic Rhodnius prolixus do colonise rural houses. PLoS Negl Trop Dis 24: e210.

Guhl F 2007a. El control de la transmisión vectorial. In OPAS, La enfermedad de Chagas a la puerta de los 100 años del conocimiento de una endemia americana ancestral, PAHO/CD/426-6, Fundación Mundo Sano, Publicación Monográfica 7, Buenos Aires, p. 129-135.

Guhl F 2007b. Chagas disease in Andean countries. Mem Inst Oswaldo Cruz 102: 29-38.

Guhl F, Pinto N, Marín D, Herrera C, Aguilera G, Naranjo JM, Vallejo G 2005a. Primer reporte de Rhodnius prolixus Stal, en Elais guineensis, variedad Papúa, en plantaciones agroindustriales de Villanueva, Casanare. Biomedica 25: 158.

Guhl F, Restrepo M, Angulo VM, Antunes CM, Campbell-Lendrum D, Davies C 2005b. Lessons from a national survey of Chagas' disease transmission in Colombia. Trends Parasitol 21: 259-262.

Guhl F, Schofield CJ (eds.) 2002. Proceedings of the ECLAT-AMCHA International Workshop on Chagas' disease in the Amazon Region, Palmarí, Brazil, Universidad de los Andes, Bogotá, 174p.

Moncayo A 2003. Current epidemiological trends after the interruption of vectorial and transfusional transmission in the Southern cone countries. Mem Inst Oswaldo Cruz 98: 1-15.

OPS - Organización Panamericana de la Salud 2004. Definición de variables y criterios de riesgos para la caracterización e identificación de áreas prioritarias en el control y vigilancia de la transmisión vectorial de la enfermedad de Chagas. PAHO/dpc/ $\mathrm{cd} / 302 / 04.30 \mathrm{p}$.

Pinto N, Marín D, Herrera C, Vallejo G, Naranjo JM, Guhl F 2005. Comprobación del ciclo selvático de Rhodnius prolixus Stal en reductos de Attalea butyracea en el departamento de Casanare. Biomedica 25: 159.

Schofield CJ 1994. Triatominae: biología y control, Eurocommunica Publications, UK, p 1-79.

Schofield CJ, Dias CJP 1999. The Southern Cone initiative against Chagas' disease. Adv Parasitol 42: 1-27.

Silveira AC 2003. Modelos factibles de vigilancia de la enfermedad de Chagas. Rev Patol Trop 32: 175-184. 
Silveira AC, Rezende DF 1984. Risk measure of domestic transmission of Chagas' disease, through a new entomological indicator. Mem Inst Oswaldo Cruz 79: 51-53.

TDR - Tropical Disease Research 1998. Uruguay declared free of Chagas disease transmission. TDR News 56: 6.

TDR - Tropical Disease Research 1999. Chile and Brazil to be certified free of transmission of Chagas' disease. TDR News 59:10.
WHO - World Health Organization 2002. Control of Chagas Disease. Tech Rep Ser 905: 109.

WHO - World Health Organization 2007. Grupo de trabajo científico sobre la enfermedad de Chagas. TDR/GTC/09, Geneve.

Yamagata Y, Nakagawa J 2006. Control of Chagas' Disease. Adv Parasitol 61: 129-165. 